\title{
Chemical bond deviation in group VI hydrids
}

\author{
B.A.Okhrimenko, O.A.Yushko, K.S.Yablochkova \\ Kyiv National T. Shevchenko University, Physics Department, \\ 4 Glushkova Ave., 03127 Kyiv, Ukraine
}

Received June 5, 2012

\begin{abstract}
$A b$ initio calculations of the chemical bond deviation in molecules were carried out using Gaussian 09 software. The results correlate with the estimations of the deviation angle obtained earlier using experimental data.
\end{abstract}

Выполнены расчеты $a b$ initio угла девиации химической связи в молекулах с использованием пакета Gaussian 09. Результаты коррелируют с оценками угла девиации, полученными ранее на основании экспериментальных данных.

\section{Introduction}

In order to determine the deviation of chemical bond, it is necessary to study a force field of a molecule. Investigation of the normal vibrations of the molecule allows to estimate values of the force field in which every atom of the molecule is situated. One of the wide-spread ways to estimate the force field is to solve the reverse spectral problem of vibrational spectroscopy. At this point, the question of how to chose the model of the force field is stated. Among the variety of the force field models, the domineering place belongs to Valence-Force-Field model (VFF). In particular, an advantage of this model compared to Central-Force-Field (CFF) model is the most evident when analyzing vibrational modes of $\mathrm{CO}_{2}$ molecule. In the small vibration approximation, CFF model predicts zero value of the deformation vibration in this molecule that disagrees with experiments.

The peculiarities of VFF model can be illustrated using an example of water molecule. It is usually supposed that the direction of $\mathrm{O}-\mathrm{H}$ chemical bond in the molecule coincides with the segment connecting $O$ and $H$ nuclei. Such presupposition would be $100 \%$ justified, if VFF model would be $100 \%$ applicable in this case.
However, a number of considerations allow us to suggest that the actual force field of water molecule is somewhat different from what VFF model suggests. The center of mass of the electron shell does not coincide with the location of oxygen atom nucleus, it is somewhat displaced towards $\mathrm{H}-\mathrm{H}$ segment due to Coulomb interaction between hydrogen nuclei. This results in Coulomb component of the interaction between hydrogen atom's nucleus and the electron shell of the molecule is not directed strictly along $\mathrm{H}-\mathrm{O}$ segment, but somewhat deviates from it. Non-zero dipole moment of water molecule hints at such distribution of the electron density in the electron shell of the molecule, that allows to stipulate the presence of the effective positive charge of hydrogen atoms. Besides, due to the effective positive charge of hydrogen atoms, Coulomb repulsion must exist between them.

Taken together, these facts can be considered as additives of CFF in VFF.

If we limit ourselves by VFF model, then under the specified conditions hydrogen atom would be under an influence of two forces, one of which directed along $\mathrm{O}-\mathrm{H}$ segment, and the second - along $\mathrm{H}-\mathrm{H}$ segment. If those two forces were equal, then their resultant would be directed along the bisector of angle $\mathrm{O}-\mathrm{H}-\mathrm{H}$. 
The speculation discussed above leads to the necessity to define the direction of a chemical bond without reference to any model. Thus in this paper, direction of chemical bond is defined as the direction corresponding to the maximum gradient of energy, characterizing the displacement of atom from its equilibrium position.

The possibility of the deviation of $\mathrm{O}-\mathrm{H}$ chemical bond direction from the segment connecting the nuclei of $\mathrm{O}$ and $\mathrm{H}$ atom resulted in introducing the term "chemical bond deviation". The angle of chemical bond deviation is the angle between the two directions described above.

The information of the real force field of a molecule can be obtained on the basis of consideration of the reverse spectral problem of vibrational spectroscopy. Using any force field model in such case is undesirable, since the features of this model influence on the result obtained. In particular, VFF model according its nature precludes an existence of deviation phenomenon, whereas CFF model does not take into account the elastic constants characterizing the bending of the chemical bonds.

Taking into account these factors, the investigations focused on deviation phenomenon were carried out using $3 N$-matrices method which does not require the presuppositions of the force field in the molecule and can be applied to molecules in condensed media. An influence of the environment on the molecule's force field is taken into account by means of using non- natural (non-eigen) vibrations frequencies in calculations.

All studies of the molecules of symmetry $C_{2 v}$ showed [2-12] that the deviation angle is different from zero. Similar results were obtained for molecules of symmetry $C_{3 \mathrm{v}}$ [13-16].

Since in all of these papers the deviation angles have been found by means of processing the experimental data, the existence of chemical bond deviation can be seen as an experimental fact.

To our best knowledge there are no papers that calculate the chemical bond deviation $a b$ initio for now. Thus, current paper aims at the estimation of the chemical bond deviation in molecules $\mathrm{H}_{2} \mathrm{O}, \mathrm{H}_{2} \mathrm{~S}, \mathrm{H}_{2} \mathrm{Se}$ and $\mathrm{H}_{2} \mathrm{Te}$ using Gaussian 09 software package.

\section{Results}

Hydrides of the elements of periodic table group VI were subjected to the study. These molecules were chosen due to their relative simplicity and their deep examining in previous investigations. Since the scope of the paper was to make initial estimates of the deviation angle, the authors chose the basic set $3-21 \mathrm{G}$ for Hartree-Fock method.

Initially, the chosen molecule was set with its parameters (distance between atoms and angles between segments) similar to the known values. Then, "Opt: Geometry" optimization procedure was set in order to determine the geometry of the molecule and the corresponding minimum energy value. This energy value corresponds to the calcu-

Table 1. Geometry of hydride molecules and deviation angles obtained via Gaussian 09

\begin{tabular}{|c|c|c|c|c|c||}
\hline \multirow{2}{*}{ Molecule } & \multirow{2}{*}{$\begin{array}{c}\text { Angle between } \\
\text { X-H segments }\end{array}$} & \multirow{2}{*}{$\begin{array}{c}\text { Length of } \\
\text { X-H segments, } \AA\end{array}$} & \multicolumn{2}{|c|}{ Deviation angle } & \multirow{2}{*}{ Error } \\
\cline { 4 - 5 } & & Compression & Stretching & \\
\hline $\mathrm{H}_{2} \mathrm{O}$ & $100.035^{\circ}$ & 0.989 & $1.893^{\circ}$ & $2.168^{\circ}$ & $0.04^{\circ}$ \\
$\mathrm{H}_{2} \mathrm{~S}$ & $92.490^{\circ}$ & 1.329 & $0.895^{\circ}$ & $-0.020^{\circ}$ & $0.2^{\circ}$ \\
$\mathrm{H}_{2} \mathrm{Se}$ & $92.531^{\circ}$ & 1.440 & $0.080^{\circ}$ & $0.890^{\circ}$ & $0.4^{\circ}$ \\
$\mathrm{H}_{2} \mathrm{Te}$ & $92.391^{\circ}$ & 1.624 & $0.409^{\circ}$ & $0.414^{\circ}$ & $0.5^{\circ}$ \\
\hline
\end{tabular}

Table 2. Experimental values of geometric parameters and deviation angles of hydride molecules

\begin{tabular}{|c|c|c|c||}
\hline Molecule & $\begin{array}{c}\text { Angle between X-H } \\
\text { segments }\end{array}$ & $\begin{array}{c}\text { Length of X-H segment, } \\
\AA\end{array}$ & Deviation angle \\
\hline $\mathrm{H}_{2} \mathrm{O}$ & $104.5^{\circ}[17]$ & $0.957[17]$ & $3.8^{\circ}[5]$ \\
$\mathrm{H}_{2} \mathrm{~S}$ & $92.1^{\circ}[17]$ & $1.34[17]$ & $6.5^{\circ}[11]$ \\
$\mathrm{H}_{2} \mathrm{Se}$ & $90.92^{\circ}[18]$ & $1.46[18]$ & $3.5^{\circ}[11]$ \\
$\mathrm{H}_{2} \mathrm{Te}$ & $90.2635^{\circ}[19,20]$ & $1.66[18]$ & $0.56^{\circ}[11]$ \\
\hline
\end{tabular}


lated equilibrium position of atoms in the molecule and will be further referred to as the energy of equilibrium position.

The first and second columns of Table 1 show the results of the geometry calculation in hydride molecules. It is important to note that the calculations results are substantially different from those obtained experimentally. The data is given in Table 2 for comparison.

In particular, the calculated value of the equilibrium angle between $\mathrm{O}-\mathrm{H}$ segments in water molecule is less than the known experimental values. The theoretical value differs from the experimental ones by more than $4^{\circ}$. Such comparatively substantial difference between the theoretical and experimental values of the angle between $\mathrm{O}-\mathrm{H}$ segments for a well-known molecule testifies to the limited accuracy of the method used.

The deviation angle was calculated in the following way. To remove ambiguity, we will consider a water molecule whose plane coincides with the plane of the page. Hydrogen atoms are located below oxygen atom symmetrically relatively to bisection of $\mathrm{H}-$ $\mathrm{O}-\mathrm{H}$ angle. For one of the atoms (usually the right one), the direction and magnitude of displacement is set. The magnitude of the displacement is chosen as $1 \%$ of the equilibrium value of the segment length. Location of the second hydrogen atom and that of oxygen atom are set unchanged. Then, energy of molecule for the given location of its atoms is estimated using "SP:Single point energy" procedure. The energy of the molecule is then calculated for other directions of hydrogen atom displacement of the same magnitudes.

The equilibrium position energy is then subtracted from the obtained values of energy and the resulting figure is plotted in polar coordinates, showing the dependence of molecule's energy on the direction of the hydrogen displacement. This plot is further referred to as the deviation loop.

Fig. 1 shows typical graphs of the loop deviation for water molecule and the molecule of hydrogen sulfide, plotted using Gaussian 09 calculations. The direction towards the maximum of the deviation loop corresponds to the direction of the chemical bond. For water molecule this direction does not coincide with the direction of the segment joining the nuclei of hydrogen and oxygen atoms. A similar conclusion holds for the molecules of hydrogen sulfide. The

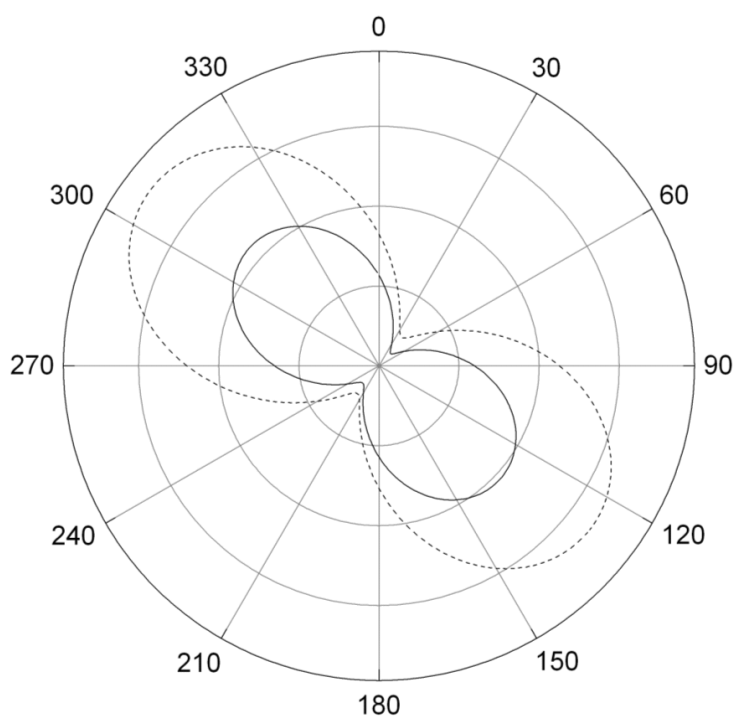

Fig. 1. Deviation loop - the graph of molecule's energy as a function of the direction of fixed magnitude displacement of one of the hydrogen's atoms. The dotted line corresponds to water molecule, the solid line corresponds to the molecule of hydrogen sulfide. In both cases, the displacement of hydrogen atom is $1 \%$ of the length of $\mathrm{O}-\mathrm{H}$ segment.

deviation angles for all the molecules studied are shown in Table 1.

Let's consider the following features of the deviation loop in Fig. 1, which are common to all curves calculated for the hydride molecules in this paper. This curve is almost symmetric with respect to the straight line connecting its maxima. The same feature of deviation loop has been shown earlier. It was found to be typical for the cases in which the displacement of hydrogen atom was small compared to the bond length [2-12].

The upper maximum of the deviation loop is located in the range of $300^{\circ}$ to $330^{\circ}$ (Fig. 1) and corresponds to the compression of the bond, i.e. to the decrease in the distance $\mathrm{H}-\mathrm{O}(\mathrm{H}-\mathrm{S})$. The lower maximum located between $120^{\circ}$ and $150^{\circ}$ corresponds to an extension of the bond, i.e. to the increase in the distance $\mathrm{H}-\mathrm{O}(\mathrm{H}-\mathrm{S})$. The energy of the upper maximum is slightly higher than the energy of the lower maximum. Qualitatively similar loop, obtained in $[5,11]$, is the result of calculations in which the anharmonicity of vibrations is taken into account.

The smoothness of the deviation loop suggests a relatively small value of errors in the calculations. This applies to both graphs in Fig. 1, and to the graphs obtained by calculations for other molecules. A more 
accurate estimation of the error in determining the angle of deviation is given in the last column of Table 1 . Collectively, the described circumstances suggest that the calculations' random error does not affect the results of the calculations performed.

The deviation angles of the hydrides molecules are given in Table 1 . When performing the calculations for each molecule, the right hydrogen atoms were displaced by $1 \%$ of the respective bond lengths. These values are overall smaller than the experimentally obtained values of deviation angles listed in Table 2.

The differences in the experimental and calculated values of the equilibrium position parameters for hydrogen atoms can probably be attributed to the computational algorithms used in Gaussian 09 package. These features may also affect the calculated values of the deviation angles.

Despite the quantitative discrepancies between the calculated and experimental results, in our opinion, the most important is the fact that the calculations in Gaussian 09 package confirm the existence of a nonzero value of the deviation angle for the considered molecules.

\section{Conclusions}

One of the widely known effects of the chemical bond deviation is the bending of hydrogen bonds in liquid water. The deviation of the hydrogen bond from a straight line is estimated to be about $10^{\circ}$. This value correlates with the value of deviation angle obtained for water molecules in the liquid phase in [5]. Essentially, the bending of hydrogen bonds in liquid water should be considered as a particular case of the more general phenomenon, namely, the chemical bond deviation phenomenon, which can become apparent not only in condensed, but also in the gas state.

Current calculations serve as the further evidence of the existence of chemical bond deviation and simultaneously point to the fact that this phenomenon constitutes a rather fine physical effect. Following the last remark it is appropriate to draw attention to some of the results of previous studies. In particular, the replacement of one hydrogen atom by a halogen atom in a methane molecule leads to change in the angle of deviation of the $\mathrm{C}-\mathrm{H}$ chemical bond [16]. Moreover, the deformation of the methane molecule by means of displacement of one of its hydrogen atoms, changes the deviation angle in the remaining hydrogen bonds [21].
It is relevant to draw the attention to some of the circumstances discussed in [22, 23]. It was found that the effectiveness of medicinal preparations could dramatically change not only due to very slight changes in chemical composition, but also due to the change of their physical parameters, while maintaining the chemical composition of the drugs. This situation allows us to hope that the results of this detailed study of the deviation phenomenon may be useful in the analysis of problems in the synthesis of medicinal substances.

\section{References}

1. M.U.Bilyu, B.A.Okhrimenko, S.M.Yablochkov, Izvestiya Vuzov MV SSO SSSR, Fizika, 4, 52 (1987).

2. M.U.Bilyu, B.A.Okhrimenko, Ukr. J. Phys., 44, 326 (1999).

3. M.U.Bilyu, G.I.Gaididei, B.A., Functional Materials, 7, 543 (2000).

4. B.A.Okhrimenko, G.I.Gaididei, Ukr. J. Phys., 48, 739 (2003).

5. B.A.Okhrimenko, K.S.Yablochkova, Ukr. J. Phys., 52, 558 (2007).

6. M.U.Bilyu, B.A.Okhrimenko, Ukr. J. Phys., 46, 825 (2001).

7. G.I.Gaididei, B.A.Okhrimenko, Visnyk $K N U$, Fizika, 4, 22 (2002).

8. B.A.Okhrimenko, G.I.Gaididei, D.M.Samoilenko, Proc. of SPIE, 5507, 184 (2002).

9. M.U.Bilyu, G.I.Gaididei, B.A.Okhrimenko et al., Ukr. J. Phys., 46, 1256 (2001).

10. G.I.Gaididei, B.A.Okhrimenko, M.V.Shelehova, K.S.Yablochkova, Visnyk KNU, Fizmat Nauky, 5, 16 (2003).

11. B.A.Okhrimenko, K.S.Yablochkova, Visnyk KNU, Fizika, 4, 449 (2006).

12. B.A.Okhrimenko, O.A.Yushko, Opt. and Spectr., 110, 2, 211 (2011).

13. M.U.Bilyu, B.A.Okhrimenko, Ukr. J. Phys., 46, 466 (2001).

14. B.A.Okhrimenko, D.M Samoilenko, Visnyk KNU, Fizika, 4, 45 (2002).

15. B.A.Okhrimenko, G.I.Gaididei, D.M.Samoilenko, Functional Materials, 11, 136 (2004).

16. B.A.Okhrimenko, D.M.Samoilenko, Ukr. J. Phys., 50, 544 (2005).

17. A.A.Radcig, B.M.Smirnov, Spravochnik po Atomnoy i Molekulyarnoy Fizike, Atomizdat, Moskva (1973) [in Russian].

18. K.S.Krasnov, Molekulyarnyye Postoyannye Neorganicheskih Soedineniy, Himiya, Leningrad (1979) [in Russian].

19. J-M.Flaud, H.Burger, Ph.Arcas et al., J.Mol. Spectr, 183, 310 (1997).

20. J-M.Flaud, M.Betrencourt, H.Burger et al., $J$. Mol.Spectr., 182, 396 (1997).

21. O.V.Matyash, B.A.Okhrimenko, Ukr. J. Phys., 54, 1167 (2009). 
22. A.Adrien, Selective Toxicity: The PhysicoChemical Basis of Therapy, Chapman \& Hall, London (1985).

23. H.van de Waterbeemd, G.Folkers and R.Guy, Eds., Pharmacokinetic Optimization in Drug
Research. Biological, Physicochemical, and Computational Strategies, Chimica Acta and Wiley-VCH, Zurich (2001).

\section{Девіація хімічного зв'язку в молекулах гідридів шостої групи}

\section{Б.А.Охріменко, О.А.Юшко, К.С.Яблочкова}

Виконано розрахунки ab initio кута девіації хімічного зв'язку в молекулах $\mathrm{H}_{2} \mathrm{O}$, $\mathrm{H}_{2} \mathrm{~S}, \mathrm{H}_{2} \mathrm{Se}$ i $\mathrm{H}_{2}$ Te з використанням пакета Gaussian 09. Результати корелюють з оцінками кута девіації, отриманими раніше на підставі експериментальних даних. 